\title{
Structural exploration on powder diffraction a nice tool for rexamination of phase diagram
}

\author{
M.H. Chambrier, F. Goutenoire \\ Université du Maine, Laboratoire des Oxydes et Fluorures UMR6010, \\ Av. O. Messiaen, Le Mans, 72000, France \\ Marie-helene.chambrier.etu@univ-lemans.fr
}

\begin{abstract}
:
The aim of this work is the structural exploration of the $\mathrm{La}_{2} \mathrm{O}_{3}-\mathrm{WO}_{3}$ phase diagram. Indeed, like many phase diagrams $\mathrm{La}_{2} \mathrm{O}_{3}-\mathrm{WO}_{3}$ was built in the $70 \mathrm{~s}$, but definite compounds structures were not determined and are still unknown. In the present contribution, we focus on $\mathrm{La}_{6} \mathrm{~W}_{2} \mathrm{O}_{15}, \mathrm{La}_{2} \mathrm{WO}_{6}$ and $\mathrm{La}_{14} \mathrm{~W}_{8} \mathrm{O}_{45}$. These compounds are synthesized as powder by solid state reaction and characterized by X-ray powder diffraction, gravimetric and differential thermal analysis.
\end{abstract}

Keywords:

Phase diagram, X-ray diffraction, structural determination

\section{INTRODUCTION}

Oxides in the family $\mathrm{Ln}_{2} \mathrm{O}_{3}-\mathrm{MO}_{3}(\mathrm{M}=\mathrm{Mo}$ and $\mathrm{W})$ were studied in the past for their refractory, nuclear materials, laser host and ferroelectric applications. More recently, oxide ionic conduction has been discovered in the molybdate and the tungstate high temperature form of $\mathrm{La}_{2} \mathrm{M}_{2} \mathrm{O}_{9}(\mathrm{M}=\mathrm{Mo}$ and $\mathrm{W})[1,2]$. Maybe associated with this last physical property, the low thermal conductivity at high temperature behavior has been pointed out for $\mathrm{La}_{2} \mathrm{Mo}_{2} \mathrm{O}_{9}$ [3].

As for the $\mathrm{La}_{2} \mathrm{O}_{3}-\mathrm{MoO}_{3}$ phase diagram [4] many reported compositions were not correctly characterized in the $\mathrm{La}_{2} \mathrm{O}_{3}$ $\mathrm{WO}_{3}$ system [5] (Figure 1). We can mentioned, the doubtful cubic form of $\mathrm{La}_{6} \mathrm{WO}_{12}$ [6] and the pseudo pyrochlore of formula $\mathrm{La}_{10} \mathrm{~W}_{2} \mathrm{O}_{21}$.

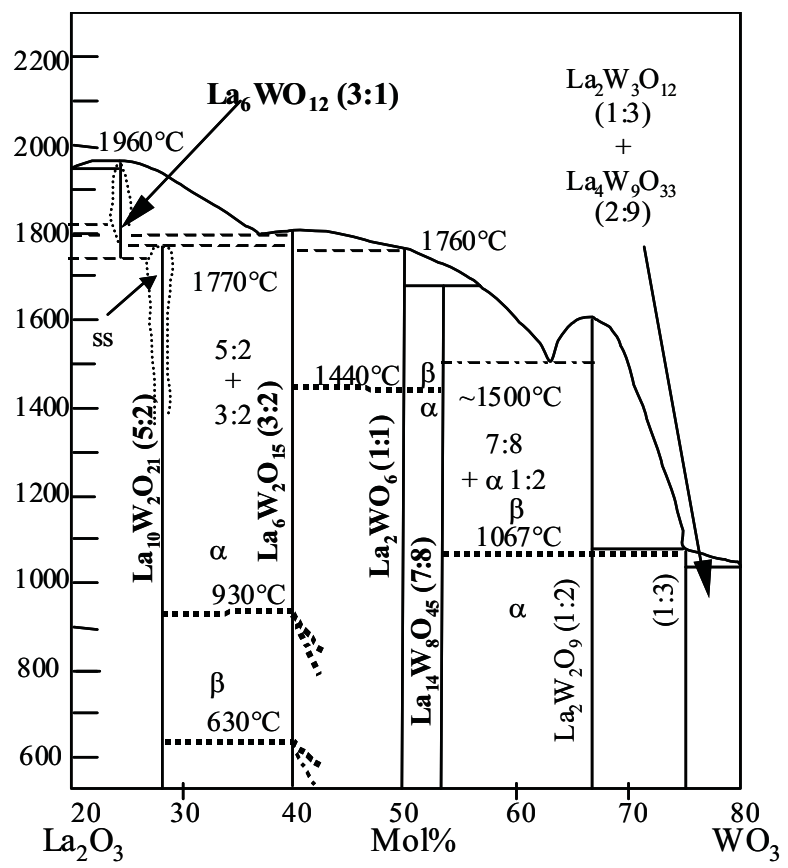

Figure 1 : Yoshimura $\mathrm{La}_{2} \mathrm{O}_{3}-\mathrm{WO}_{3}$ phase diagram.
The definite compound $\mathrm{La}_{10} \mathrm{~W}_{2} \mathrm{O}_{21}$ could not be presented here because of the lack of results. $\mathrm{La}_{6} \mathrm{~W}_{2} \mathrm{O}_{15}, \mathrm{La}_{2} \mathrm{WO}_{6}$ and $\mathrm{La}_{14} \mathrm{~W}_{8} \mathrm{O}_{45}$ crystallographic studies will be treated in the present paper.

\section{EXPERIMENTAL}

\subsection{Synthesis}

These compounds were prepared with $\mathrm{La}_{2} \mathrm{O}_{3}$ and $\mathrm{WO}_{3}$ as starting oxides by solid state reaction. Lanthanum oxide powder was dried and decarbonated at $1000^{\circ} \mathrm{C}$ overnight prior to use. The oxides were weighed in stoechiometric proportions and ground together in an agate mortar. The prepared compositions were heated up in a temperature range $1300-1600^{\circ} \mathrm{C}$ depending of $\mathrm{WO}_{3}$ molar $\%$ for one night in an alumina crucible, no particular condition was used in order to cool down the samples. For the X-ray measurement a small amount $(\sim 0.5 \mathrm{~g})$ of the compounds with final formula used. . All three compounds $\mathrm{La}_{6} \mathrm{~W}_{2} \mathrm{O}_{15}$, $\mathrm{La}_{2} \mathrm{WO}_{6}$ and $\mathrm{La}_{14} \mathrm{~W}_{8} \mathrm{O}_{45}$ are white in color.

\subsection{Characterization}

The room temperature and high-temperature X-ray diffraction patterns were recorded on a Bragg-Brentano diffractometer (MPD-PRO Panalytical) with copper radiation equipped with a linear detector X'Celerator (Ni Filter) and a Anton Paar HTK12 furnace.

The electron diffraction study was performed on a $200 \mathrm{kV}$ side entry JEOL2010 transmission electron microscope with a double-tilt specimen holder operating at room temperature. The sample was prepared by grinding a small amount of powder in an agate mortar and pestle under dry 1-butanol to produce a suspension. A drop of the suspension was deposited on a holey carbon film supported by a 1000 mesh copper grid and dried.

The density measurement was performed on a gas picnometer ACCUPIC 1330 (Micromeritics) with helium as gas using approximately $2 \mathrm{~g}$ of sample. The temperature of measurement was $24^{\circ} \mathrm{C} \pm 1^{\circ} \mathrm{C}$.

\section{$3 \mathrm{La}_{6} \mathrm{~W}_{2} \mathrm{O}_{15}$}

This definite compound located at $40 \mathrm{WO}_{3}$ molar \% undergoes two allotropic transformations at 600 and $960^{\circ} \mathrm{C}$ characterized by TDA and X-ray diffraction (Figure 2).

This is an Open Access article distributed under the terms of the Creative Commons Attribution-Noncommercial License (http://creativecommons.org/licenses/by-nc/3.0/), which permits unrestricted use, distribution, and reproduction in any noncommercial medium, provided the original work is properly cited. 


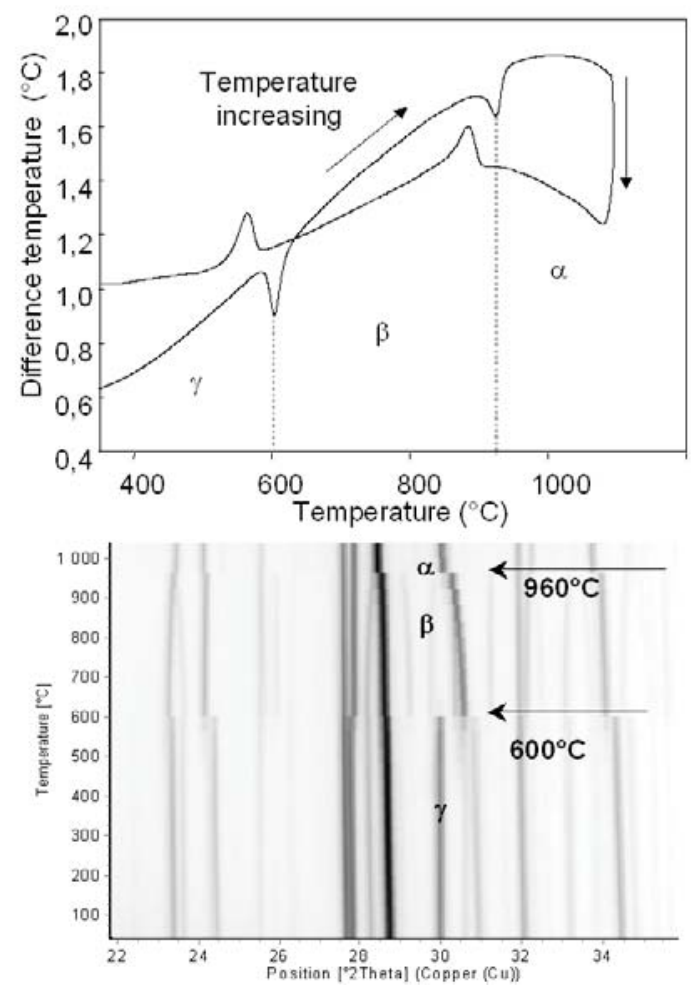

Figure 2: above, differential temperature analysis of $\mathrm{La}_{6} \mathrm{~W}_{2} \mathrm{O}_{15}$ showing two endothermic peaks on heating and two exothermic peaks on cooling. Below, thermo-diffraction data plot as Guinier film. The three different crystallographic forms present similar strong peaks.

An attentive study of the three allotropic X-ray diagrams easily shows a structural relation between these three forms. At room temperature, the crystallographic problem seems difficult, no cell parameters were easily found. Attempts were done by electronic diffraction in SAED mode with no success. The intermediate and high temperature forms present more symmetric structures, which are easier to analyze.

\section{- High temperature}

From the analysis of the $\mathrm{X}$-ray powder diffraction data collected on the MPD-PRO at $1000^{\circ} \mathrm{C}$, we were able to obtain good solutions from two different autoindexing programs Treor [7] and Dicvol [8] implemented in X'Pert High Score Plus [9]. The solutions determined by both programs are very similar: $a=12.688 \AA ; b=9.198 \AA, c=$ $5.985 \AA, V=698.43 \AA^{3}$, with a figure of merit $M_{20}=25.0$ [10] and $M_{20}=85.0$ respectively for Treor and Dicvol.

The structure solution was determined by Monte Carlo analysis performed by the program Espoir [11] in scratch mode, using only the first 66 peaks. These peaks were extracted by a Le Bail fit in the space group $\mathrm{Cmmm}$ from the $\mathrm{X}$-ray data. Distance constraints were used between $L a-W<3.3 \AA$, La-La $<3.7 \AA$ and $W-W<3.3 \AA$, in order to help in the search of these atomic positions. Three particular space groups give a better solution (Rp around 10\%), with other space groups $\mathrm{C}_{\ldots} \ldots$ _ nothing better than Rp $>25 \%$ was obtained. For the three good space groups, the previous cationic positions were refined, leading to: $R_{\text {Bragg }}=18.7,18.8$ and $21.7 \%$, respectively for $\mathrm{C} 222{ }_{1}\left(\mathrm{~N}^{\circ} 20\right), \mathrm{Ccmm}\left(\mathrm{N}^{\circ} 63\right)$ and $\mathrm{Ccm} 2{ }_{1}\left(\mathrm{~N}^{\circ} 36\right)$. The cationic solutions are listed in table 1 , these solutions are really similar (Figure 3 ). Attempts to find all the oxygen atomic positions from the X-ray data were very difficult due to the strong difference of the diffusion factor between $\mathrm{W}^{+6}(68 \mathrm{e}-), \mathrm{La}^{3+}(54 \mathrm{e}-)$ and $\mathrm{O}^{2-}(10 \mathrm{e}-)$.
Table 1: Cationic positions of $\alpha-L a_{6} W_{2} \mathrm{O}_{15}$ obtained by Espoir from the $X$-ray data

\begin{tabular}{|c|c|c|c|c|}
\hline & \multicolumn{5}{|c|}{$C \mathrm{c} \mathrm{m} \mathrm{m} \mathrm{(No.} \mathrm{63)}$} \\
\hline Atom & Wyck. & $\mathbf{x}$ & $\mathbf{y}$ & $\mathbf{z}$ \\
\hline La1 & 8 & 0.39 & 0.71 & 0.75 \\
\hline La2 & 4 & 0.09 & 0.5 & 0.75 \\
\hline W1 & 4 & 0.69 & 0.5 & 0.75 \\
\hline & \multicolumn{5}{|c|}{$C$ c m $2_{1}($ No. 36 ) } \\
\hline Atom & Wyck. & $\mathbf{x}$ & $\mathbf{y}$ & $\mathbf{z}$ \\
\hline La1 & $8 b$ & 0.61 & 0.29 & 0.24 \\
\hline La2 & $4 a$ & 0.09 & 0.5 & 0.73 \\
\hline W1 & $4 a$ & 0.69 & 0.5 & 0.76 \\
\hline & \multicolumn{2}{|c|}{$C 222_{1}($ No. 20$)$} \\
\hline Atom & Wyck. & $\mathbf{x}$ & $\mathbf{y}$ & $\mathbf{z}$ \\
\hline La1 & $8 \mathrm{c}$ & 0.61 & 0.79 & 0.52 \\
\hline La2 & $4 a$ & 0.40 & 0.5 & 0.5 \\
\hline W1 & $4 a$ & 0.19 & 0.5 & 0 \\
\hline
\end{tabular}
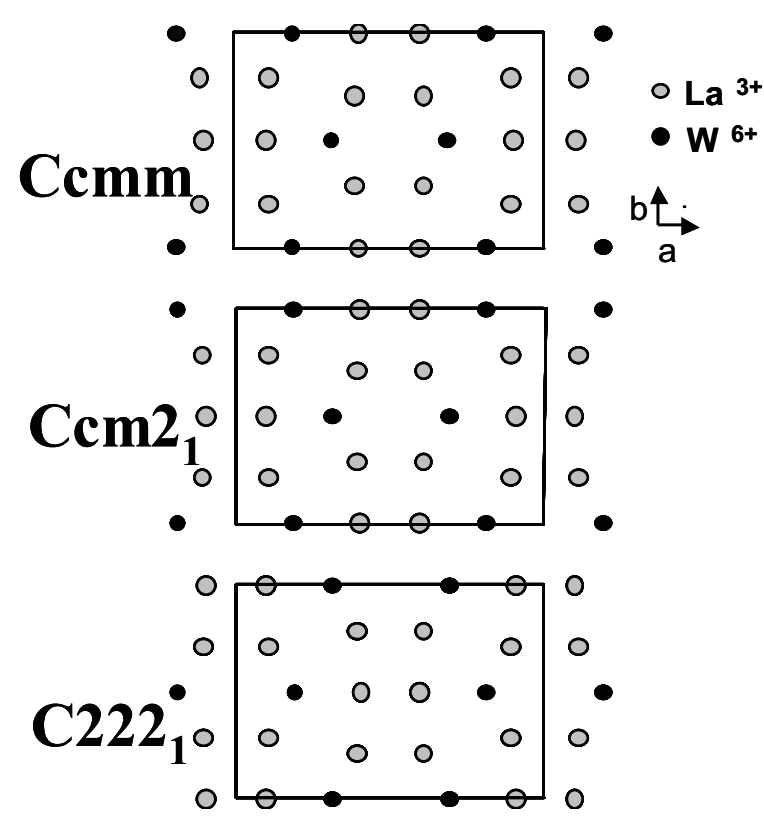

Figure 3: projection along $\mathrm{c}$ axis of the three best cationic solutions. The three models are similar, it could be described as six lanthanum atoms in $(2 \times 3)$ shape surrounded by six tungsten atoms in a hexagonal shape.

With the cationic solution only, it was possible to present the cell evolution for the three different forms and it will be enough to mention a new phase around $42 \%$. With the analysis of X-ray diffraction data and Fourier difference, it was possible to find an equivalent oxygen position for the three solutions. This oxygen position results in a tetrahedral environment of lanthanum atoms forming an $\mathrm{OLa}_{4}$ entity. Such tetrahedra form an infinite double ribbon along the $c$ direction of formula $\left[\mathrm{O}_{2} \mathrm{La}_{3}\right]_{\infty}$. So, this analysis implies a $\mathrm{W}_{2} \mathrm{O}_{11}$ polyhedron. Such polyhedron was observed in the same phase diagram in the low temperature form $\mathrm{La}_{2} \mathrm{WO}_{6}$ (see here after). In this compound, the $\mathrm{W}_{2} \mathrm{O}_{11}$ polyhedron is formed by two octahedra sharing one vertex. In the present compound the $\mathrm{W}-\mathrm{W}$ distance is too large $5.55 \AA$, which has to be compared with the same distance of $4.13 \AA$ in $\mathrm{La}_{2} \mathrm{WO}_{6}$. Then, the $\mathrm{W}_{2} \mathrm{O}_{11}$ polyhedron is formed by a strong oxygen disorder as $\mathrm{WO}_{5.5}$. One can then understand the 
two lower phase transitions as an ordering of such strong disorder and it will also explain the discovery of a new phase around the nominal composition (see New phase here after). The complete structural solution will be presented in a dedicated publication [12].

- Intermediate temperature

With the high temperature cationic structure solution, it was possible to refine the two low temperature phases namely $\beta$ and $\gamma$. The evolution of the crystallographic volume with the temperature is presented on Figure 4 . For the $\beta$ and $\gamma$ forms the Rietveld refinements lead to $R_{\text {Bragg }}=15.9 / 24.98 \%$ and $R_{\mathrm{wp}}=16.56 / 23.06 \%$ respectively. In fact, these two low temperature forms present sur-structure with larger cells. For the intermediate phase $\beta$, a monoclinic cell: $a=$ $15.1068 \AA ; b=11.7707 \AA, c=7.8396 \AA, \beta=100.83^{\circ}, V=1369.2$ $\AA^{3}$ was found, with a figure of merit $M_{20}=12.5$ for the twenty first nicely observed peaks. This solution came without any un-indexed peak. The auto-indexed volume, $V=1369.2 \AA^{3}$ is also closely related to the cell volume of the alpha form $V^{\prime}=2 \times 688=1376 \AA^{3}$ for the same temperature [13].

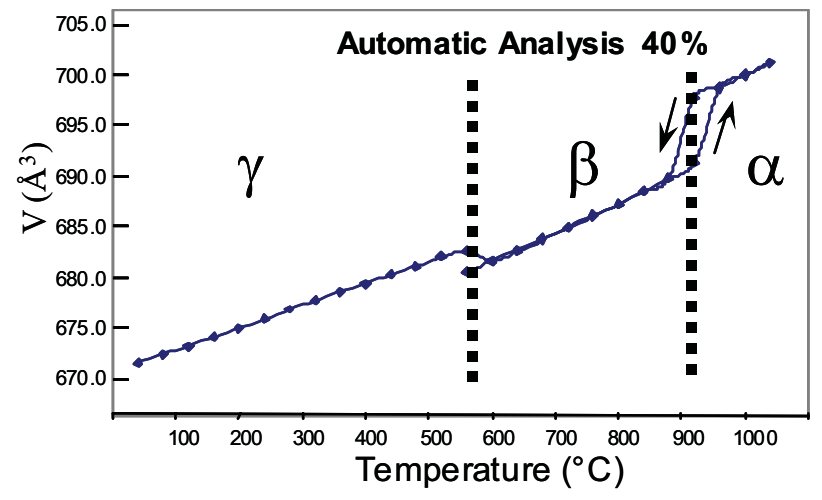

Figure 4 : cell evolution of the three crystallographic forms obtained from an automatic refinement with the cationic model of the high temperature form

- New phase

On the phase diagram proposed by Yoshimura see Figure 1 , the phase transitions of $\mathrm{La}_{6} \mathrm{~W}_{2} \mathrm{O}_{15}$ present an unusual behavior in the range $40-50 \mathrm{WO}_{3} \%$ in contrast with the range 28.8-40 $\mathrm{WO}_{3} \%$. There is a decrease and disappearance of the both phase transitions around the composition $41 \%$, whereas no evolution is observed in the range of $28.8-40 \mathrm{WO}_{3} \%$. Such behavior was also observed in this study. Fine analysis of the diffraction patterns leads to a new phase around $42 \%$ in $\mathrm{WO}_{3}$, see Figure 5 . This new phase has in fact the same structure as the $\alpha$ $\mathrm{La}_{6} \mathrm{~W}_{2} \mathrm{O}_{15}$ but stabilized at room temperature. Electron diffraction analysis reveals that a modulated structure is observed, only with one modulation vector along the a axis. The explanation of such modulated structure could be interpreted with the knowledge of the strong oxygen disorder observed for the high temperature form of $\mathrm{La}_{6} \mathrm{~W}_{2} \mathrm{O}_{15}$. The nominal composition for the new compound is around $42 \mathrm{~mol} \%$ of $\mathrm{WO}_{3}$. Such composition leads to the formula $\mathrm{La}_{6} \mathrm{~W}_{2.172} \mathrm{O}_{31.032}$, so close to an extra oxygen atom. This could be an indication.

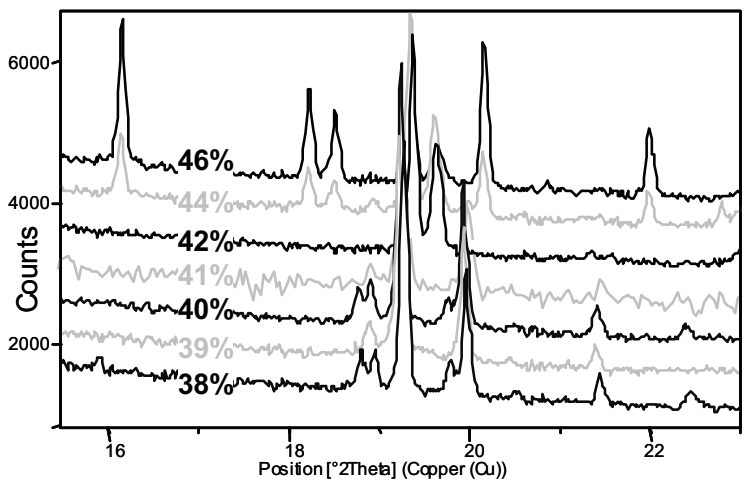

Figure 5 : details of the X-ray powder diffraction patterns for the series 38 to $46 \%$. The lower patterns correspond to $\mathrm{La}_{6} \mathrm{~W}_{2} \mathrm{O}_{15}(40 \%)$, the higher composition patterns correspond mainly to $\mathrm{La}_{2} \mathrm{WO}_{6}(50 \%)$. With a fine analysis, it is possible to observe a new diffraction pattern for $42 \%$, corresponding to a new phase.

\section{$4 \mathrm{La}_{2} \mathrm{WO}_{6}$}

In the series of $\mathrm{Ln}_{2} \mathrm{MO}_{6}$ with $\mathrm{Ln}=$ Lanthanide and $\mathrm{M}=$ $\mathrm{Mo}, \mathrm{W}$, the compound $\mathrm{La}_{2} \mathrm{WO}_{6}$ is the last one with an unknown structure. This compound presents a reversible phase transformation at $1440^{\circ} \mathrm{C}$ observed by differential thermal analysis. The low temperature form is labeled $\beta$ $\mathrm{La}_{2} \mathrm{WO}_{6}$

$\beta$-La $\mathrm{WO}_{6}$ crystallizes in an orthorhombic space group $\mathrm{P} 2{ }_{1} 2{ }_{1}{ }_{1}$ (n $\left.{ }^{\circ} 59\right), a=7.5196$ (1) $\AA, b=10.3523$ (1) $\AA, c=$ 12.7989 (1) $\AA$. There are 18 atoms in asymmetric positions leading to 54 refined parameters (xyz). $\mathrm{La}^{3+}$ ions are eight folded and $\left[\mathrm{W}_{2} \mathrm{O}_{11}\right]$ units are formed by two octahedra linked by vertex [14]. Such $\left[\mathrm{W}_{2} \mathrm{O}_{11}\right]$ units are observed on figure 6. As for the high temperature of $\mathrm{La}_{6} \mathrm{~W}_{2} \mathrm{O}_{15}$, there is only one oxygen atom, which is not linked to any tungsten atom. This oxygen atom is surrounded by four lanthanum atoms in a tetrahedral environment.

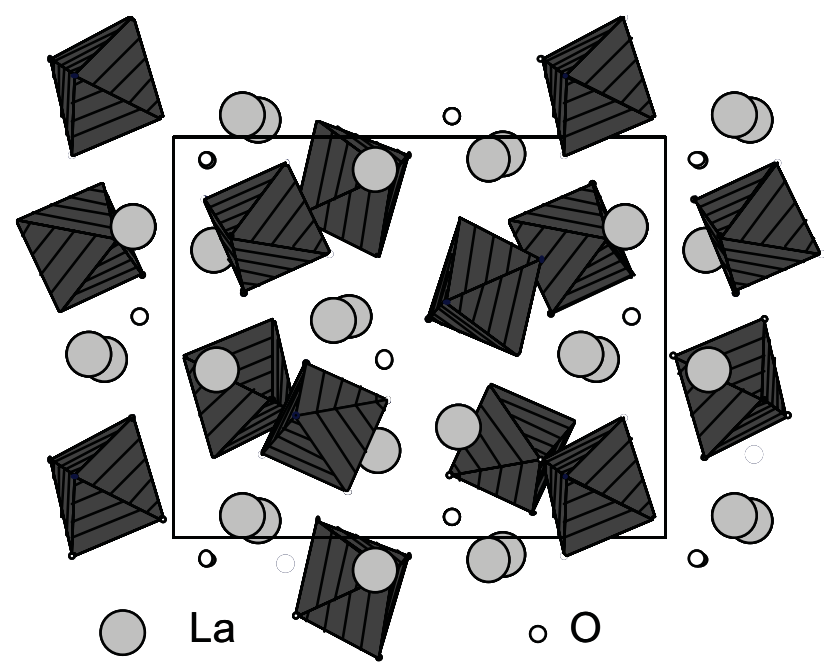

Figure 6 : projection along the a axis of $\mathrm{La}_{2} \mathrm{WO}_{6}$, hatched polyhedra represent $\mathrm{WO}_{6}$ octahedra. $\mathrm{W}_{2} \mathrm{O}_{11}$ units formed by two octahedra linked by one vertex could be observed. One oxygen atom is not linked to tungsten atoms. This oxygen atom is surrounded by 4 lanthanum atoms in a tetrahedral environment.

\section{$5 \quad \mathrm{La}_{14} \mathrm{~W}_{8} \mathrm{O}_{45}$ \\ - Structural determination}

During ab-initio structural determination, the composition was improved from $\mathrm{La}_{14} \mathrm{~W}_{8} \mathrm{O}_{45}$ to $\mathrm{La}_{18} \mathrm{~W}_{10} \mathrm{O}_{57}$. The $\mathrm{WO}_{3}$ molar \% difference between the two compounds is very 
small $0.7 \%$. The compound $\mathrm{La}_{14} \mathrm{~W}_{8} \mathrm{O}_{45}$ corresponds to 53.3 and $\mathrm{La}_{18} \mathrm{~W}_{10} \mathrm{O}_{57} 52.6$ to $\mathrm{WO}_{3}$ molar \%. The X-ray diffraction pattern was indexed in a hexagonal cell with parameters of $a=9.0448(1) \AA$ and $c=32.6846(3) \AA$. This tungstate crystallizes in the non-centrosymmetric hexagonal space group $\left(n^{\circ} 190\right) P-62 c$, with $Z=2$ and a measured density $7.28(3) \mathrm{g} . \mathrm{cm}^{-3}$. The structure presents a subcell $c^{\prime}=c / 6=5.45 \AA$, see figure 7 for instance. This structure presents some interesting structural features: some tungsten atoms are coordinated in an unusual prismatic environment and some tungsten atoms form a chain of octahedra linked by face sharing. The unusual prismatic polyhedron was observed before only in the compounds $\mathrm{Ln}_{3} \mathrm{WO}_{6} \mathrm{Cl}_{6}$ [15]. The chain is composed of four octahedra. In order to have corrected tungsten-tungsten distance, the two tungsten atoms in the center of the chain are statistically occupied. The complete structure solution and analysis was published in a dedicated article [16].

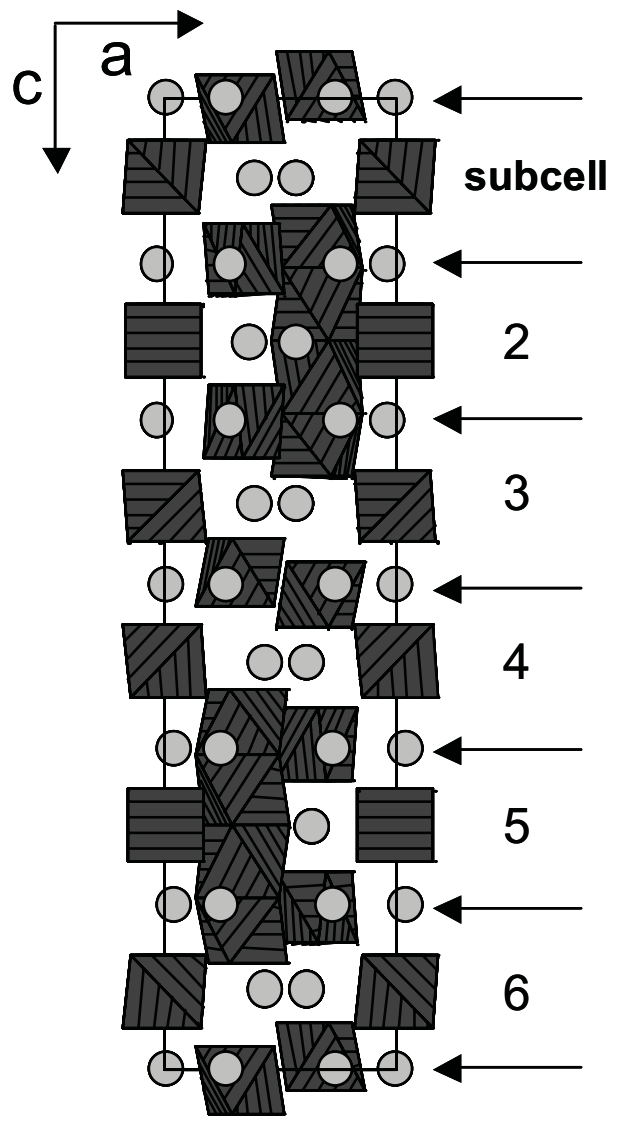

Figure 7 : projection on the plane (ac) of the structure $\mathrm{La}_{18} \mathrm{~W}_{10} \mathrm{O}_{57}$. The subcell and the $6 \mathrm{H}$ polytype are marked. With careful observation the chain of four octahedra could be observed.

\section{- Polytypism}

In a previous study from Yanovskii [17], it was not possible to resolve the structure due to a lack of good crystals. Nevertheless, they notice the commonest six-layered polytype which belongs to the space group $\mathrm{P} 6_{3} / \mathrm{mmc}$ (no piezoeffect detected) with cell parameters $a=9.04(1) \AA$ and $c=32.60-33.65 \AA$ depending on the composition of the crystal. Different polytypes of ' $\mathrm{La}_{2} \mathrm{WO}_{6}{ }^{\prime}$ [18] on single crystals were presented (namely $4 \mathrm{H} \quad \mathrm{C}=22.01 \AA, 5 \mathrm{H}$ $\mathrm{c}=27.25 \AA, 6 \mathrm{H} \mathrm{c}=32.64 \AA, 7 \mathrm{H} \mathrm{c}=38.40 \AA$, etc...). In order to understand and reproduce this phenomenon, syntheses $\mathrm{s}$ were carried out with varying the $\mathrm{WO}_{3}$ molar percent between 52 to $53.6 \%$ by small steps of the $0.33 \%$. On the Figure 8, from 52 to $52.6 \%$, we observed a rapid

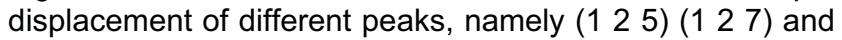

(0 113 ) at higher or lower 2 theta positions. From 52.6 to $53.6 \%$ no displacement was evidenced. Contrary to the precedent electron diffraction study, analysis for the $52 \%$ compound revealed a probable $\times 7$ superstructure. However, attempts to solve the structure from conventional X-ray data were unsuccessful. So it could be possible that between 50 to $52.6 \mathrm{WO}_{3} \%$ several polytypes coexist. No evidence of a relation between the sequence of polytypes and the chemical composition was considered.

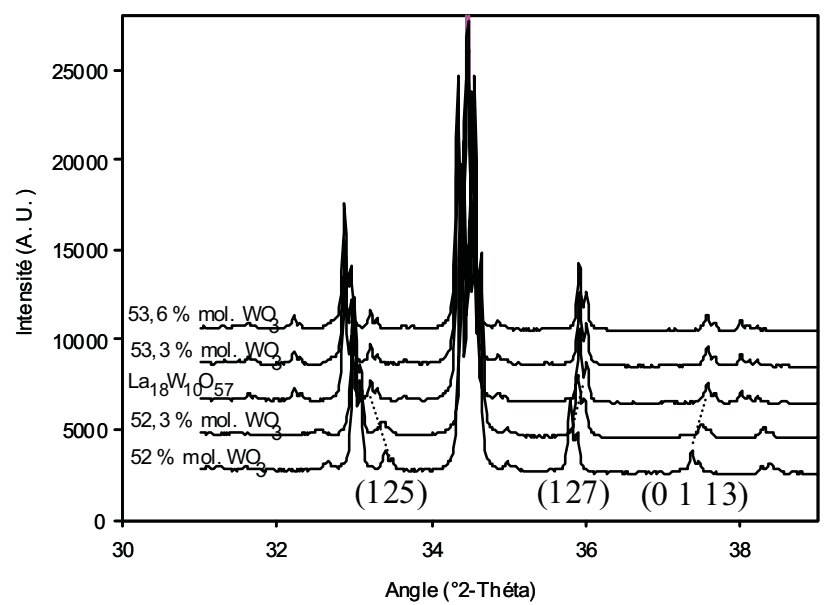

Figure 8 : powder diffraction patterns from the serie (52 to $53.6 \mathrm{WO}_{3} \mathrm{~mol} \%$ ). From 52 to the nominal composition namely $\mathrm{La}_{18} \mathrm{~W}_{10} \mathrm{O}_{57}$ strong displacements of different peaks are observed. These displacements are marked with dashed lines. From the nominal composition to 53.6 no displacement is observed.

\section{CONCLUSION}

Diffraction analysis has always been a nice tool to evaluate phase diagram. Here, it has been intensively used to make the re-investigation of an old phase diagram with a large number of known formulas without any structural analysis.

The first compound of formula $\mathrm{La}_{6} \mathrm{~W}_{2} \mathrm{O}_{15}$ has been partially characterized in its high temperature form at $1000^{\circ} \mathrm{C}$. The structure could be described as formed with $\left[\mathrm{O}_{2} \mathrm{La}_{3}\right]$ infinite ribbon and $\mathrm{WO}_{5.5}$ polyhedron. The last polyhedron presents a strong disorder and the two low temperature forms could be interpreted as an ordering of such disorder. With a partial crystallographic model, it has been possible to refine the two low temperature phases. Then such low temperature forms could be interpreted as a sur-structure of the high temperature form.

A new compound with a nominal composition around 42 mol $\mathrm{WO}_{3} \%$ has been evidenced. This new compound also nicely explains the ambiguous thermal behavior in the two phase transitions of $\mathrm{La}_{6} \mathrm{~W}_{2} \mathrm{O}_{15}$.

The structure solution of $\beta-\mathrm{La}_{2} \mathrm{WO}_{6}$ permits to solve the stronger crystallographic problem in the serie $\mathrm{Ln}_{2} \mathrm{WO}_{6}$. But its high temperature form is still unsolved.

The structure solution of the previous composition $\mathrm{La}_{14} \mathrm{~W}_{8} \mathrm{O}_{45}$ has modified the phase diagram. In fact, the real composition was not exactly $\mathrm{La}_{14} \mathrm{~W}_{8} \mathrm{O}_{45} \quad(53.3 \%)$ but $\mathrm{La}_{18} \mathrm{~W}_{10} \mathrm{O}_{57}(52.6 \%)$. Such revision is of course due to the real knowledge of the structure. Around this composition it has been possible to observed another polytype $7 \mathrm{H}$, but no structural information and chemical composition relation were obtained. Nevertheless, the region between 50 to $52.6 \%$ should be considered are formed by many $\mathrm{nH}$ polytypes. 


\section{ACKNOWLEDMENT}

We thank Uday Krishna Ravella for the proof correction.

\section{REFERENCES}

[1] Lacorre P., Goutenoire F., Bohnke O., Retoux R., Laligant Y., 2000, Designing fast oxide-ion conductors based on $\mathrm{La}_{2} \mathrm{Mo}_{2} \mathrm{O}_{9}$, Nature, 404, 856-858.

[2] Marrero-Lopez D., J. Pena-Martınez J., Ruiz-Morales J.C, Nunez P., 2008, Phase stability and ionic conductivity in substituted $\mathrm{La}_{2} \mathrm{~W}_{2} \mathrm{O}_{9}$, J. Solid State Chemistry 181, 253-262.

[3] Winter M. R., Clarke D. R., 2007, Oxide Materials with low thermal conductivity, J. Am. Ceram. Soc, 90 [2] 533-570.

[4] Fournier J. P., Fournier J., Kohlmuller R., 1970, Etude des systèmes $\mathrm{La}_{2} \mathrm{O}_{3}-\mathrm{MoO}_{3}, \mathrm{Y}_{2} \mathrm{O}_{3}-\mathrm{MoO}_{3}$, et des phases $\mathrm{Ln} \mathrm{n}_{6} \mathrm{MoO}{ }_{12}$ Bull. Soc. Chim. Fr., 12, 4277-4279.

[5] Yoshimura M., Rouanet A., 1976, System $\mathrm{La}_{2} \mathrm{O}_{3}-\mathrm{WO}_{3}$. High-temperature phase diagram, Mater. Res. Bull., 11, $151-158$.

[6] Haugsrud R. , Kjølseth C., 2008, Effects of protrons and acceptor substitution on the electrical conductivity of La6 WO 12 Journal of Physics and chemistry of Solids.

[7] Werner P.-E. , 1985, TREOR, a semi-exhaustive trial-and-error powder indexing program for all symmetries, J. Appl. Cryst., 18, 367-370.

[8] Boultif A. ,Louër D. , 1991, Indexing of powder diffraction patterns for the low-symmetry lattices by the succesives dichotomy method, J. Appl. Cryst., 24, 987-993.

[9] X'Pert High Score Plus, producted by PANalytical B.V., Almelo, Nerterlands, version 2.0.1, 2004.

[10] De Wolff P. M., 1968, A simplified criterion for the reliability of a powder pattern indexing, J Appl. Cryst., 1, 108 (1968).

[11] Le Bail A.,2000, « Program Espoir 3.5 », http://sdpd.univ-lemans.fr/sppd/espoir/.

[12] Chambier M-H , Ibberson R.M., Goutenoire F., 2008, Structure Determination of $\alpha-\mathrm{La}_{6} \mathrm{~W}_{2} \mathrm{O}_{15}$, submitted to J. of Solid State Chemistry.

[13] Chambier M-H , Goutenoire, in preparation, Structure Determination of $\beta-\mathrm{La}_{6} \mathrm{~W}_{2} \mathrm{O}_{15}$.

[14] Chambrier M-H., Kodjikian S., Ibberson R.M., Goutenoire F., 2009, Ab-initio structure determination of $\beta$-La ${ }_{2} W_{6}$, Journal of Solid State Chemistry, 182, 209-214.

[15] Brixner L.H., Chen H.Y. and Foris C.M., 1982, Structure and luminescence of some rare earth halotungstates of type $\mathrm{Ln}_{3} \mathrm{WO}_{6} \mathrm{Cl}_{6}$, J. Solid State Chem., 44, 99-107.

[16] Chambrier M-H., Le Bail A., Kodjikian S., Suard E., Goutenoire F., Structure Determination of $\mathrm{La}_{18} \mathrm{~W}_{10} \mathrm{O}_{56}$, accepted to Inorganic Chemistry.

[17] Yanovskii V.K., Voronkova V.I.,1975, Crystallography and properties of lanthanum oxytungstate, La $\mathrm{WO}_{6}$, Sov. Phys. Crystallogr., 20, 354-355.

[18] Yanovskii V. K. and Voronkova V. I,1981, Polytisme of La $\mathrm{WO}_{6}$ crystals, Sov. Phys. Crystallogr. 26(3), 341-342. 